\title{
Maintenance of Axo-Oligodendroglial Paranodal Junctions Requires DCC and Netrin-1
}

\author{
Andrew A. Jarjour, ${ }^{1,2}$ Sarah-Jane Bull, ${ }^{1,2}$ Mohammadali Almasieh, ${ }^{4}$ Sathyanath Rajasekharan, ${ }^{1,2}$ K. Adam Baker, ${ }^{1,2}$ \\ Jeannie Mui, ${ }^{3}$ Jack P. Antel, ${ }^{1,2}$ Adriana Di Polo, ${ }^{4}$ and Timothy E. Kennedy ${ }^{1,2,3}$ \\ ${ }^{1}$ Montreal Neurological Institute, Departments of ${ }^{2}$ Neurology and Neurosurgery and ${ }^{3}$ Anatomy and Cell Biology, McGill University, Montreal, Quebec, \\ Canada H3A 2B4, and ${ }^{4}$ Department of Pathology and Cell Biology, Université de Montréal, Montreal, Quebec, Canada H3T 1J4
}

\begin{abstract}
Paranodal axoglial junctions are essential for the segregation of myelinated axons into distinct domains and efficient conduction of action potentials. Here, we show that netrin- 1 and deleted in colorectal cancer (DCC) are enriched at the paranode in CNS myelin. We then address whether netrin-1 signaling influences paranodal adhesion between oligodendrocytes and axons. In the absence of netrin-1 or DCC function, oligodendroglial paranodes initially develop and mature normally but later become disorganized. Lack of DCC or netrin-1 resulted in detachment of paranodal loops from the axonal surface and the disappearance of transverse bands. Furthermore, the domain organization of myelin is compromised in the absence of netrin- 1 signaling: $\mathrm{K}^{+}$channels inappropriately invade the paranodal region, and the normally restricted paranodal distribution of Caspr expands longitudinally along the axon. Our findings identify an essential role for netrin-1 and DCC regulating the maintenance of axoglial junctions.
\end{abstract}

Key words: myelin; axoglial junction; paranode; septate-like junctions; Caspr; neurofascin

\section{Introduction}

The functional division of myelinated axons into distinct domains is crucial for the establishment of saltatory conduction. Concentrated at nodes of Ranvier are high densities of voltagegated sodium channels that depolarize the axonal membrane, generating and propagating the action potential (for review, see Poliak and Peles, 2003). Flanking the node are the paranodal axoglial junctions, where each layer of the myelin sheath terminates in a cytoplasm-filled membrane loop that tightly abuts the axon. The paranode separates the node from the juxtaparanodal domain, the outermost region of the internode (for review, see Poliak and Peles, 2003). Concentrated at the juxtaparanode are Shaker-type voltage-gated potassium channels, which maintain internodal resting potential by preventing hyperexcitation and action potential backpropagation after nodal $\mathrm{Na}^{+}$influx (Wang et al., 1993; Chiu et al., 1999; Vabnick et al., 1999). The molecular mechanisms that regulate the formation and maintenance of paranodal junctions are not well understood.

The tight association between paranodal axonal and glial membranes is thought to act as a barrier between the node and

\footnotetext{
Received July 14, 2008; revised Aug. 26, 2008; accepted Sept. 8, 2008.

This work was supported by grants from the Multiple Sclerosis Society of Canada and Canadian Institutes of Health Research. A.A.J., S.-J.B., and S.R. were supported by Multiple Sclerosis Society of Canada studentships, and K.A.B. was supported by a Jeanne Timmins Costello Fellowship from the Montreal Neurological Institute. T.E.K. is a Killam Foundation Scholar and holds a Chercheur Nationaux Award from Fonds de la Recherche en Santé du Québec. We thank Liliana Pedraza, Alejandro Roth, David Colman, Nina Bauer, and Anna Williams for comments on this manuscript and Hojatollah Vali for expert guidance regarding electron microscopy.

Correspondence should be addressed to Timothy E. Kennedy, Centre for Neuronal Survival, Montreal Neurological Institute, McGill University, 3801 University Avenue, Montreal, Quebec, Canada H3A 2B4. E-mail: timothy.kennedy@mcgill.ca.

DOI:10.1523/JNEUROSCI.3285-08.2008

Copyright $\odot 2008$ Society for Neuroscience $\quad 0270-6474 / 08 / 2811003-12 \$ 15.00 / 0$
}

the juxtaparanode, isolating electrical activity at the node of Ranvier from the internode and preventing the lateral diffusion of axonal proteins among domains (Poliak and Peles, 2003). Ultrastructurally, the points of contact between oligodendrocyte and axolemmal membranes are characterized by the presence of electron-dense ridges called transverse bands (Tao-Cheng and Rosenbluth, 1983). The axonal protein Caspr, also called paranodin, or ncp 1, is concentrated at the paranode during myelination (Einheber et al., 1997). Caspr forms a complex in cis with the GPI (glycosylphosphatidylinositol)-linked protein contactin (Rios et al., 2000), and this association is required for the localization of Caspr to the axonal membrane (Faivre-Sarrailh et al., 2000). The recruitment of the Caspr-contactin complex to the paranodal domain is dependent on the presence of the $155 \mathrm{kDa}$ isoform of neurofascin (nfc155). Nfc155 forms a complex with Caspr and contactin in trans, and all three are essential for the formation of normal paranodal axoglial junctions in both the CNS and PNS (Tait et al., 2000; Bhat et al., 2001; Boyle et al., 2001; Charles et al., 2002; Sherman et al., 2005; Bonnon et al., 2007). In the absence of either Caspr or contactin, transverse bands do not form, the close association between many paranodal loops and the axon is disrupted, and potassium channels are mislocalized to the paranodal region (Bhat et al., 2001; Boyle et al., 2001). Similar phenotypes are generated by loss of either ceramide galactosyl transferase (CGT) or myelin and lymphocyte protein (MAL), which are required for the proper trafficking of nfc155 (Dupree et al., 1999; Schaeren-Wiemers et al., 2004; Schafer et al., 2004).

In the adult rat spinal cord, oligodendrocytes express netrin-1 and its receptor, deleted in colorectal cancer (DCC) (Manitt et al., $2001,2004)$. Netrins are a small family of $\sim 75 \mathrm{kDa}$ proteins with homology to laminins. They are best known as secreted chemotropic guidance cues for migrating cells and axons. Signaling 
through DCC, they direct the reorganization of F-actin by regulating focal adhesion kinase (FAK), fyn, PI-3 kinase, and the Rho-GTPases Cdc42 and Racl (Moore et al., 2007). Additionally, they contribute to tissue morphogenesis by regulating cell-cell and cell-matrix adhesion; however, this is best understood outside the CNS (for review, see Baker et al., 2006). Subcellular fractionation of adult rat spinal cord white matter indicated that netrin-1 is enriched in fractions containing noncompact myelin membranes (Manitt et al., 2001). These membrane preparations typically contain proteins present at points of axoglial contact, including the paranodal junction (Menon et al., 2003). We demonstrate that DCC and netrin-1 are enriched at oligodendroglial paranodes and that, in the absence of netrin-1 or DCC function, CNS paranodes develop and mature normally, but this organization is subsequently lost. The essential contribution of netrin- 1 and DCC to paranodal maintenance, but not formation, distinguishes the phenotypes reported here from those found previously in other mutants, and suggests that distinct mechanisms regulate the organization of the paranodal axoglial junction in the developing and mature CNS. In summary, our findings demonstrate that netrin- 1 and its receptor DCC are required for the maintenance of paranodal axoglial contact and represent the first reported function for netrin-1 in the mature CNS.

\section{Materials and Methods}

Animals. Adult male Sprague Dawley rats (180$200 \mathrm{~g}$ ) and newborn CD1 mouse pups were obtained from Charles River Canada. Mice heterozygous for netrin-1 or DCC function were obtained from Marc Tessier-Lavigne (Genentech, San Francisco, CA) and Robert Weinberg (Whitehead Institute for Biomedical Research, Cambridge, MA), respectively, and bred into a $\mathrm{CD}-1$ genetic background. All procedures with animals were performed in accordance with the Canadian Council on Animal Care guidelines for the use of animals in research.

Antibodies. The following primary antibodies were used in this study: mouse monoclonal anti-Caspr (University of California Davis NeuroMab; catalog \#75-001), guinea pig polyclonal anti-Caspr, rabbit polyclonal anti-Caspr (gift from Dr. David Colman, McGill University, Montreal, Quebec, Canada) (Svenningsen et al., 2003), mouse monoclonal anti-DCC intracellular domain (DC$\mathrm{C}_{\mathrm{IN}}$ ) (BD Biosciences Pharmingen; catalog \#554223), rabbit polyclonal anti-Kv1.2 (Alomone Labs; catalog \#APC-010), mouse monoclonal antimyelin basic protein (MBP) (Millipore Bioscience Research Reagents; catalog \#MAB382), rabbit polyclonal anti-MBP (Millipore Bioscience Research Reagents; catalog \#AB9046), rat monoclonal anti-MBP (Millipore Bioscience Research Reagents; catalog \#MAB386), rabbit polyclonal anti-netrin PN2 (Manitt et al., 2001), rabbit polyclonal anti-neurofascin $100 \mu \mathrm{m}$.
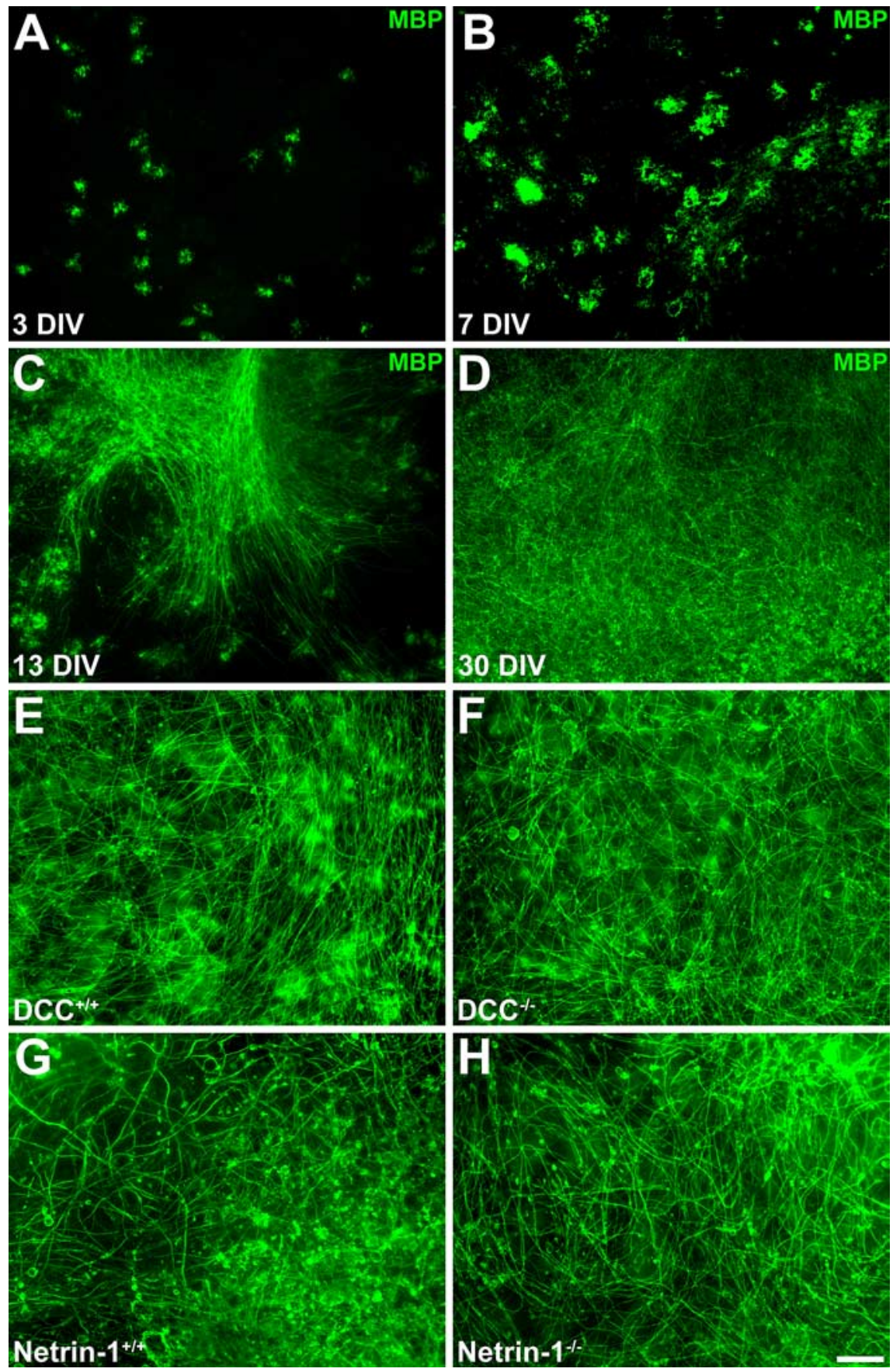

Figure 1. Normal myelin formation in wild-type and netrin-1 and DCC mutant cerebellar organotypic cultures. Oligodendrocyte maturation and myelination in slices of newborn mouse cerebellum follows a similar time course to that in vivo and occurs normally in the absence of netrin and DCC. After 3 DIV, oligodendrocytes, immunolabeled with an antibody against MBP and visualized using Alexa 488-conjugated secondary antibodies (green), can be readily detected (A). They increase in number and complexity between 3 and 7 DIV (B). By 14 DIV, many myelinated axons are visible (C), and by 30 DIV, extensive myelination is observed throughout the white matter $(\boldsymbol{D})$. Abundant myelination is observed in long-term slice cultures derived from both DCC ${ }^{-/-}$and netrin-1 ${ }^{-/-}$mutant animals $(\boldsymbol{F}, \boldsymbol{H})$ and their wild-type littermates $(\boldsymbol{E}, \boldsymbol{G})$. Magnification: $20 \times$ objective. Scale bar, burgh, UK; recognizes both 155 and $186 \mathrm{kDa}$ isoforms of neurofascin) (Tait et al., 2000), mouse monoclonal anti-neurofilament $145 \mathrm{kDa}$ (NFM) (Millipore Bioscience Research Reagents; catalog \#MAB1621), chicken polyclonal anti-NFM (EnCor Biotechnology; catalog \#CPCANF-M), chicken polyclonal anti-neurofilament $200 \mathrm{kDa}$ (NFH) (EnCor; catalog \#CPCA-NF-H), mouse anti-myelin proteolipid protein (PLP) (Millipore Bioscience Research Reagents; catalog \#MAB388), mouse 
monoclonal anti-sodium channel (pan) $\left(\mathrm{Na}^{+} \mathrm{ch}\right)$ (Sigma-Aldrich; catalog \#S8809). Secondary antibodies used were Alexa 488conjugated donkey anti-mouse (catalog \#A21202) and goat anti-rabbit (catalog \#A11008), Alexa 546-conjugated goat antimouse (catalog \#A11030) and goat anti-rabbit (catalog \#A11010), Alexa 633-conjugated goat anti-chicken (catalog \#A21103) and goat antimouse (catalog \#A21052), and Alexa 647conjugated donkey anti-rabbit (catalog \#A21244) from Invitrogen, and rhodamineconjugated donkey anti-guinea pig (Jackson ImmunoResearch; catalog \#706-295-148).

Immunocytochemistry and confocal analysis of adult rat spinal cord. Adult rats were anesthetized with sodium pentobarbital (Somnotol; 65 $\mathrm{mg} / \mathrm{kg}$, i.p.; MTC Pharmaceuticals) and perfused transcardially with PBS, followed by $4 \%$ paraformaldehyde (PFA) in PBS at pH 7.4. Spinal cords were then equilibrated in $30 \%$ sucrose in PBS for $48 \mathrm{~h}$ at $4^{\circ} \mathrm{C}$, embedded in optimal cutting temperature compound (Sakura Finetek), $18 \mu \mathrm{m}$ longitudinal and coronal cryosections cut, and processed for immunohistochemistry. Images were captured using a Zeiss LSM 510 confocal microscope. In all cases, single confocal slices were collected.

Immunocytochemistry and confocal analysis of cerebellar slice cultures. Cerebellar slice cultures were prepared based on previously published methods (Notterpek et al., 1993). Briefly, after decapitation, brains were dissected into icecold HBSS and $250 \mu \mathrm{m}$ sagittal slices of cerebellum and attached brainstem were cut using a McIlwain tissue chopper. The tissue slices were placed on Millipore Millicell-CM organotypic culture inserts (Thermo Fisher Scientific) in medium containing 50\% MEM with Earle's salts, 25\% Earle's balanced salt solution, 25\% heat-inactivated horse serum (HIHS),
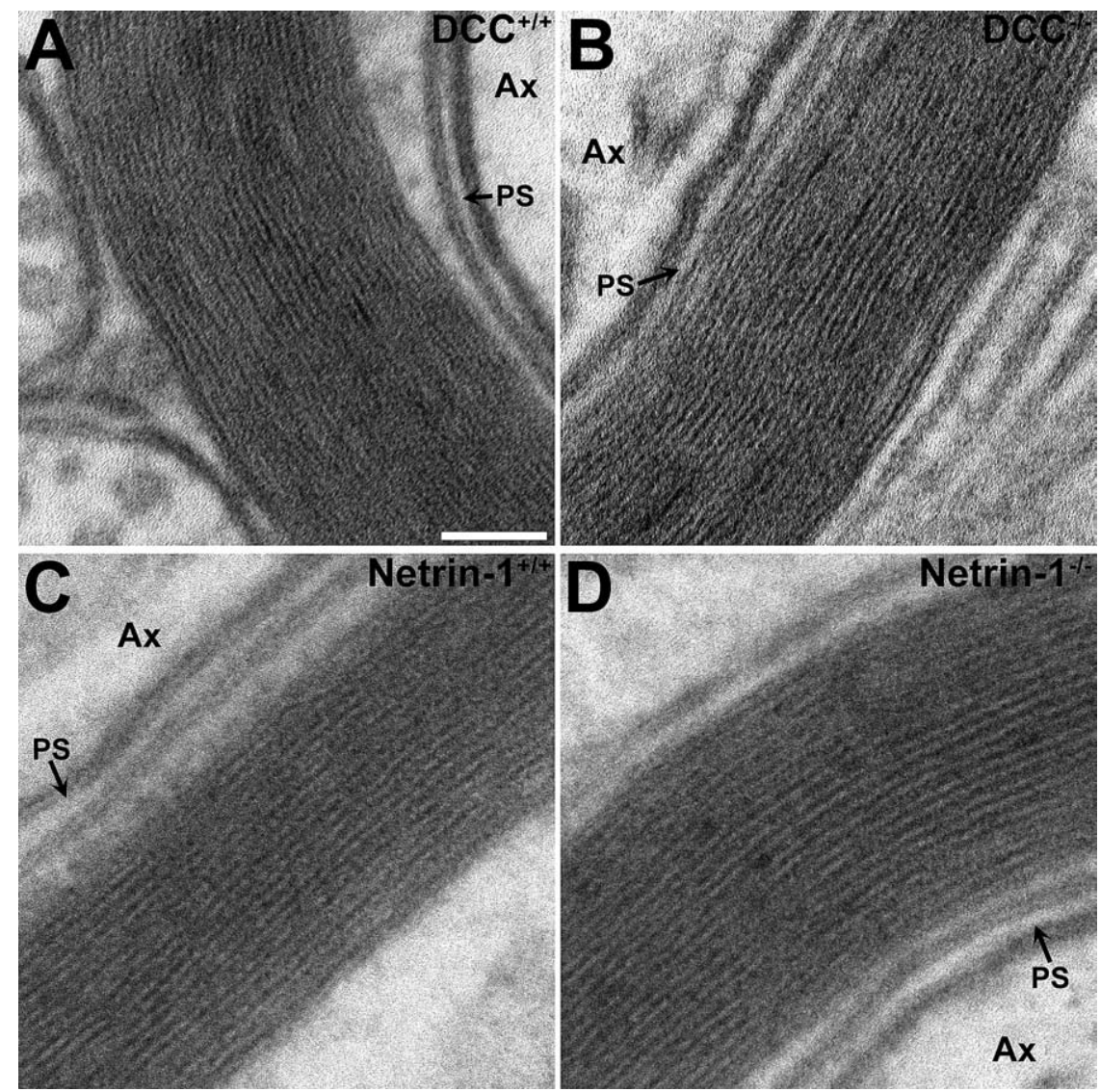

Figure 2. Compact myelin ultrastructure is normal in long-term netrin-1 and DCC mutant cerebellar slice cultures. Spacing between layers of the myelin sheath was analyzed by transmission electron microscopy in cross sections cut from cerebellar slice cultures derived from $\mathrm{DCC} \mathrm{C}^{-1-}$ or netrin-1 ${ }^{-1-}$ animals $(\boldsymbol{B}, \boldsymbol{D}$, respectively) and their wild-type littermates $(\boldsymbol{A}, \boldsymbol{C}$, respectively). The width of the periaxonal space was unaffected in the mutant slices. Although the periodicity of netrin- $1^{+/+}$and netrin- $1^{-1-}$ myelin wraps was not significantly different, the absence of DCC expression resulted in a small $(\sim 11 \%)$, but significant, increase in the spacing between layers of compact myelin (supplemental Table 1, available at www.jneurosci.org as supplemental material). Electron micrographs were imaged at 410,000×. Ax, Axon; PS, periaxonal space. Scale bar, $50 \mathrm{~nm}$.

glutamax-II supplement with penicillin-strep-

tomycin, amphotericin B (all purchased from Invitrogen), and 6.5 $\mathrm{mg} / \mathrm{ml}$ glucose (Sigma-Aldrich). Membranes were transferred into fresh medium every $2 \mathrm{~d}$. Slices processed after $25 \mathrm{~d}$ in vitro (DIV) are referred to in the text as "short-term cultures," and those processed at 7 weeks in vitro or later (49 DIV for netrin mutant litters processed for EM, 67 DIV for DCC mutant litters processed for EM, and 60 DIV for netrin-1 and DCC mutant litters processed for confocal analysis) are referred to as "long-term cultures."

Slices processed for immunolabeling were fixed while attached to membranes with 4\% PFA in PBS for $1 \mathrm{~h}$, rinsed in PBS for $10 \mathrm{~min}$, and blocked with 3\% HIHS, 2\% BSA, $0.25 \%$ Triton X-100 in PBS for $2 \mathrm{~h}$. Slices were then incubated in primary antibody $36-48 \mathrm{~h}$, washed once for $10 \mathrm{~min}$ and then thrice for $1 \mathrm{~h}$, incubated in secondary antibody overnight, washed, and mounted.

Confocal images were captured as described above. For analysis of sodium and potassium channel distribution, slices were labeled with mouse anti- $\mathrm{Na}^{+} \mathrm{ch}$ and rabbit anti-Kv1.2 antibodies. The plane chosen for imaging was that at which nodal $\mathrm{Na}^{+} \mathrm{ch}$ and juxtaparanodal Kv1.2 immunoreactivity was closest. The distance between $\mathrm{Na}^{+} \mathrm{ch}$ and Kv1.2 channel expression, and the length of the $\mathrm{Na}^{+}$ch channel immunoreactivity were analyzed. For analysis of neurofascin localization, the distance between the outermost edges of the region of neurofascin immunoreactivity was measured. The plane chosen for imaging was that in which the node of Ranvier most evenly bisects the region of neurofascin immunolabeling. For analyses of Caspr immunoreactivity, the length of each Caspr expression domain was measured. For analyses of neurofascin and Caspr localization, slices were also labeled with chicken anti-NFH and mouse anti-MBP antibodies. Distances were measured using LSM 510 Image Browser software.

Electron microscopy. Slices and attached membrane were cut out from surrounding membrane and fixed overnight with $2.5 \%$ glutaraldehyde in $0.1 \mathrm{~m}$ sodium cacodylate buffer, osmicated with potassium ferrocyanidereduced $1 \%$ osmium tetroxide solution for $1 \mathrm{~h}$, and then dehydrated with successive $10 \mathrm{~min}$ rinses in $30,50,70,80,95$, and $100 \%$ ethanol (three times). Tissue was then infiltrated with 1:1, 1:2, and 1:3 ethanol to Epon blends, and then in pure Epon, for $1 \mathrm{~h}$ each, and then embedded in Epon, tissue side down, in a plastic BEEM capsule (Structure Probe). The 70$100 \mathrm{~nm}$ sections were then cut onto 200 mesh copper grids and stained with $4 \%$ uranyl acetate for $5 \mathrm{~min}$, followed by Reynolds's lead citrate for $3 \mathrm{~min}$.

Images were observed using a transmission electron microscope at 80 $\mathrm{kV}$ using a JEM-2000FX (JEOL; used for all analyses except for those of short-term netrin mutant cultures) or at $120 \mathrm{kV}$ using a Tecnai 12 (FEI) Gatan Bioscan CCD camera. For each condition, at least two slices from each of two animals were analyzed. For analyses of compact myelin, the width of the periaxonal space at each axon was measured, and the periodicity of compact myelin was calculated. For analyses of paranodal myelin, because of technical limitations encountered during the embedding process, only single paranodes were analyzed at a time. Each paranode was examined for the presence of four "faults." A paranode was credited with a fault if the majority of paranodal loops present lacked transverse bands; if neighboring paranodal glial membranes lacked electron density between apposed glial loops and these membranes were separated by two or more membrane widths ("interloop densities"); if at 


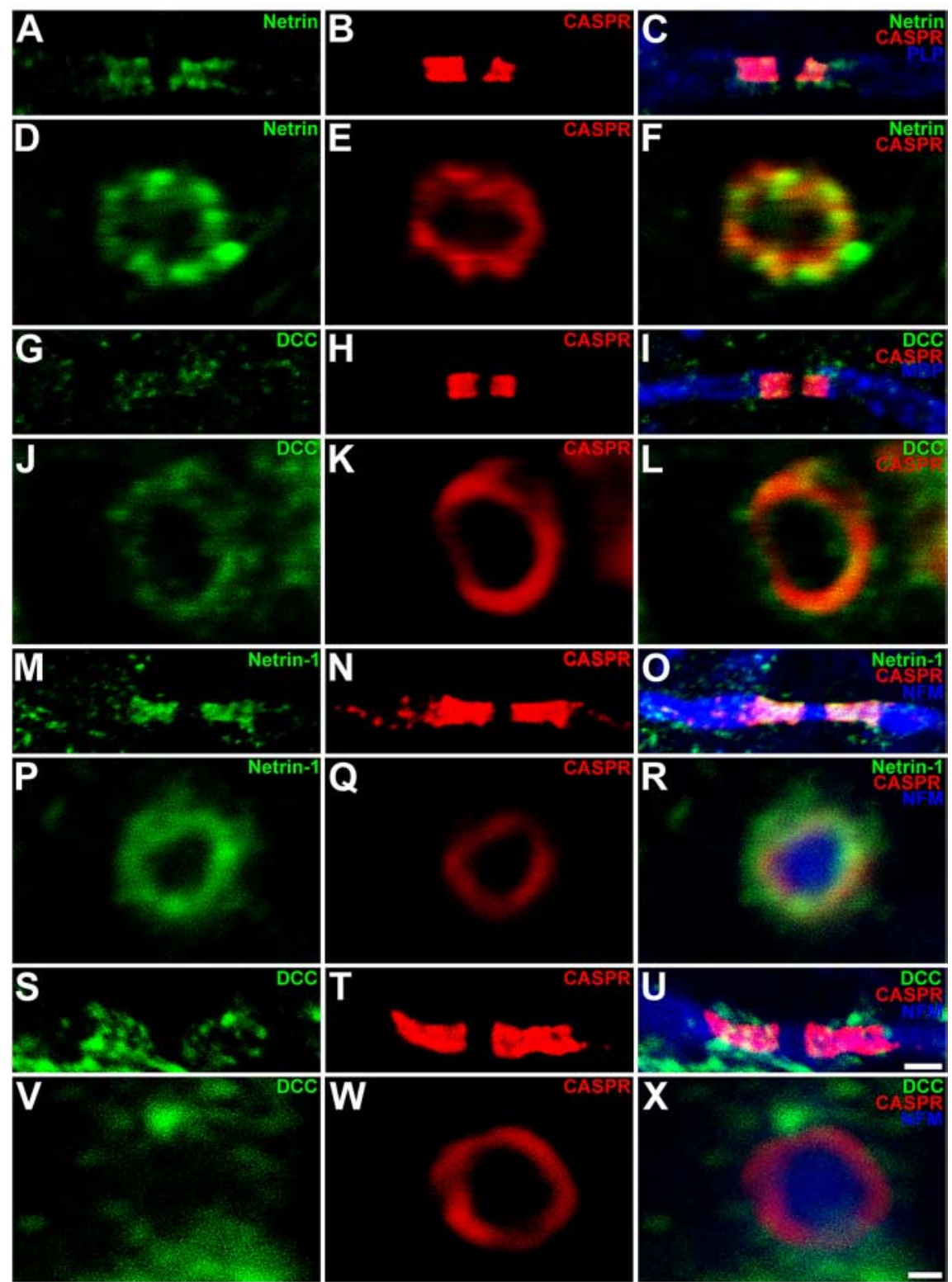

Figure 3. Distribution of netrin- 1 and $D C C$ in myelinated cerebellar organotypic slice cultures and adult rat spinal cord. Triplelabel immunohistochemical analysis of longitudinal $(\boldsymbol{A}-\boldsymbol{C}, \mathbf{G}-\mathbf{I}, \mathbf{M}-\mathbf{O}, \mathbf{S}-\boldsymbol{U})$ and cross-sectional $(\boldsymbol{D}-\boldsymbol{F}, \boldsymbol{J}-\boldsymbol{L}, \boldsymbol{P}-\boldsymbol{R}, \boldsymbol{V}-\boldsymbol{X})$ images of the paranode in mature (30 DIV) cerebellar slice cultures $(\boldsymbol{A}-\boldsymbol{L})$ and adult rat spinal cord $(\boldsymbol{M}-\boldsymbol{X})$. Caspr immunoreactivity was visualized using Alexa 546-conjugated secondary antibodies (red). PLP (C), MBP (I), and $\operatorname{NFH~}(\boldsymbol{O}, \boldsymbol{R}, \boldsymbol{U}, \boldsymbol{X})$ immunoreactivity was visualized using Alexa 633-conjugated secondary antibodies (blue). Netrin-1 and DCC proteins were visualized using Alexa 488conjugated secondary antibodies (green). Netrin-1 protein $(\boldsymbol{A}-\boldsymbol{F}, \boldsymbol{M}-\boldsymbol{R})$ is localized to the paranodal axoglial junction, where it is closely associated, and partially overlaps with Caspr. $D C C$ protein $(G-L, S-X)$ surrounds the axon at the paranode but does not colocalize with Caspr to the same extent as netrin-1. Magnification: $\boldsymbol{A}-\boldsymbol{C}, \mathbf{G}-\mathbf{I}, \mathbf{M}-\mathbf{O}, \mathbf{S}-\boldsymbol{U}, 100 \times$ objective; digital zoom, 4; D-F, $J-L, P-R, V-\boldsymbol{X}, 100 \times$ objective; digital zoom, 10. Scale bars: $A-C, G-I, M-0, S-U, 2 \mu \mathrm{m} ; \mathbf{D}-\boldsymbol{F}, \boldsymbol{J}-\mathbf{L}, \mathbf{P}-\boldsymbol{R}, \boldsymbol{V}-\boldsymbol{X}, 500 \mathrm{~nm}$.

least one paranodal loop had detached from the axonal surface by two or more membrane widths; or if at least one paranodal loop faced away from the axonal surface (depicted in Fig. $5 A$ ).

Oligodendrocyte precursor cell transplantation into retina and immunohistochemical analysis in vivo. Oligodendrocyte precursor cells (OPCs) were purified by shake-off from a mixed glial culture derived from neonatal mouse cortices, as previously described (Jarjour et al., 2003). $\mathrm{DCC}^{-1-}$ mice (CD-1 genetic background) were identified behaviorally and their cortices were cultured separately from their wild-type and heterozygote littermates. Genotypes were subsequently confirmed by PCR. Isolated OPCs were concentrated to a density of $15,000 \mathrm{cells} / \mu \mathrm{l}$ in OLDEM (oligodendrocyte defined medium) as described by us (Jarjour et al., 2003). The OPC suspension $(2 \mu \mathrm{l})$ was injected into the vitreous chamber of the left eye of wild-type 2-monthold male CD-1 mice using a $10 \mu$ l Hamilton syringe with a 32 gauge glass microneedle. The needle tip was inserted into the superior (dorsal) hemisphere of the eye, at the level of the pars plana, at a $45^{\circ}$ angle through the sclera into the vitreous body as described previously ( $\mathrm{Sa}$ pieha et al., 2005). This route of administration avoided retinal detachment or injury to eye structures, including the lens and the iris. The injection was performed within 1 min to slowly deposit the OPCs onto the retinal fiber layer. The needle was then gently removed, and surgical glue (Indermill; Tyco Health Care) was used to seal the injection site. Eight weeks after the transplantation, animals were perfused transcardially with $4 \%$ PFA. Eyes were then enucleated and the retinas were removed, fixed for an additional $30 \mathrm{~min}$, and flat-mounted vitreal side up on a glass slide for examination of the ganglion cell layer. Retinal tissue was permeabilized in $2 \%$ Triton X-100, 0.5\% DMSO in PBS for $4 \mathrm{~d}$, and blocked for $2 \mathrm{~h}$ in $10 \%$ normal goat serum, $2 \%$ Triton X-100, and 0.5\% DMSO in PBS. Retinas were then incubated in primary antibodies for $48 \mathrm{~h}$ and washed once for $5 \mathrm{~min}$ and thrice for 20 min. Secondary antibodies were applied for $2 \mathrm{~h}$, and retinas were washed and mounted on slides. Images were collected and analyses performed as described for organotypic slices.

\section{Results}

Long-term, myelinating cerebellar organotypic cultures

Netrin-1 and DCC are expressed by myelinating oligodendrocytes in the mature CNS (Manitt et al., 2001, 2004). To investigate possible roles of netrin-1 and DCC in myelination, we sought to examine CNS white matter in the absence of netrin-1 or $d c c$ expression. However, mice lacking functional netrin-1 or DCC protein die within hours of birth (Serafini et al., 1996; Fazeli et al., 1997), weeks before the vast majority of CNS myelin forms in rodents. To circumvent this limitation, we established organotypic cerebellar slice cultures derived from either newborn [postnatal day 0 (P0)] netrin-1 or dcc knock-out mice and their wild-type littermates.

In the developing rat cerebellum, MBPpositive oligodendroglia are first observed at P2 and increase in number throughout the white matter by P7. Myelinated axon segments are first observed at P7, and increase in abundance by $\mathrm{P} 12$, with extensive myelination seen by P20 (Reynolds and Wilkin, 1988). A similar time course is observed during cerebellar development in mice (Foran and Peterson, 1992). The time course of oligodendroglial development in cerebellar slice cultures derived from wild-type newborn mice was similar to that observed in vivo. MBP-positive oligodendrocytes were visible at 3 DIV and increased in number and process complexity between 3 and 7 DIV. Widespread MBP-positive myelin profiles were visible by 13 DIV, and myelination was extensive by 30 DIV (Fig. 1 $A-D$ ). Using this method, we have maintained healthy myelinating cultures as long as 70 DIV. 


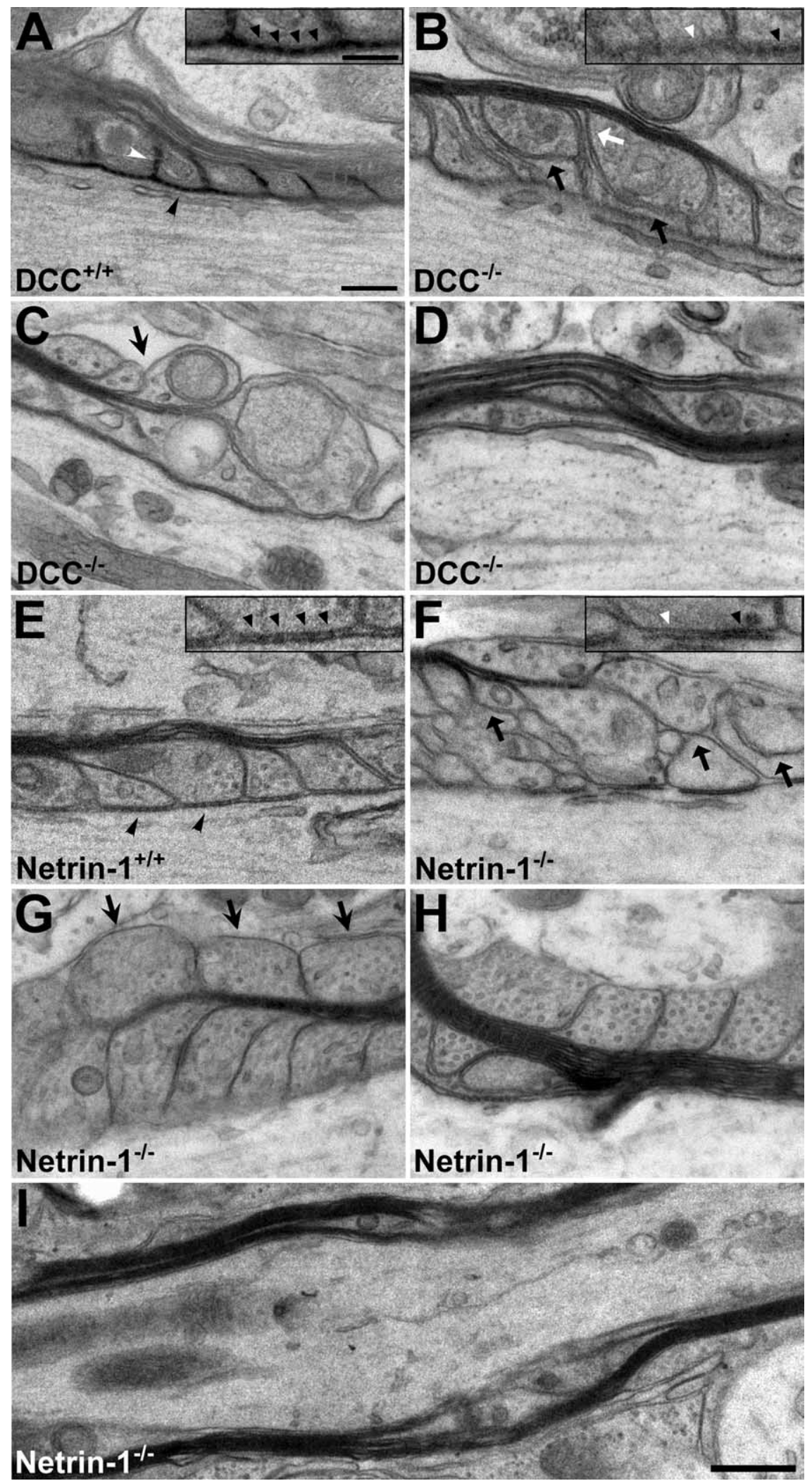

Figure 4. Abnormal paranodal myelin in long-term DCC-and netrin-1-deficient organotypic slice cultures. The organization of both paranodal and internodal myelin was examined using transmission electron microscopy in long-term $(\boldsymbol{A}-\boldsymbol{D}, 67 \mathrm{DIV} ; \boldsymbol{E}-\boldsymbol{H}, 49$ DIV) organotypic slice cultures derived from newborn DCC or netrin-1 mutant mouse cerebellum $(\boldsymbol{B}-\boldsymbol{D}, \boldsymbol{F}-\boldsymbol{H})$ or that of their wild-type littermates $(\boldsymbol{A}, \boldsymbol{E})$. In slices collected from wild-type animals, paranodal myelin was well organized, and electron-dense transverse bands between the axonal and oligodendrocyte membranes ( $\boldsymbol{A}, \boldsymbol{E}$, black arrowheads) and interloop densities between paranodal loops ( $\boldsymbol{A}$, white arrowhead) were present. In contrast, in slices lacking DCC or netrin-1, transverse bands are frequently disordered ( $\boldsymbol{B}, \boldsymbol{F}$, insets, black arrowheads) or absent ( $\boldsymbol{B}, \boldsymbol{F}$, insets, white arrowheads), and paranodal loops were often disorganized. Myelin membranes were frequently separated from the axolemma ( $\boldsymbol{B}, \boldsymbol{F}$, black arrows) and from each other ( $\boldsymbol{B}$, white
Myelin develops normally in DCC- and netrin-1-deficient cerebellar slice cultures

To investigate whether netrin- 1 and DCC are required for the proper organization of CNS myelin, cerebellar slice cultures were prepared from newborn netrin-1 and DCC mutant animals and their wild-type littermates and analyzed. Extensive MBPpositive myelin profiles were visible in long-term ( $>7$ weeks of age) wild-type, $\mathrm{DCC}^{-1-}$, and netrin-1 ${ }^{-/-}$cultures (Fig. $1 E-H)$. Compact myelin ultrastructure appeared normal in both $\mathrm{DCC}^{-1-}$ and netrin- $1^{-1-}$ cerebellar slices and those collected from their wild-type littermates (Fig. 2; supplemental Table 1, available at www.jneurosci.org as supplemental material). Major dense lines, intraperiod lines, and periaxonal spaces were clearly evident in electron micrographs of $\mathrm{DCC}^{-1-}$ and netrin- $1^{-1-}$ myelin cross sections, with the number of myelin layers routinely exceeding 10 , similar to wild-type myelin. The width of the periaxonal space (PS) was unaffected in both $\mathrm{DCC}^{-1-}$ and netrin$1^{-l-}$ slices (Fig. 2). Myelin periodicity was unaffected in netrin-1 $1^{-\prime}$ slices, although a slight increase was observed in DCC $^{-1-}$ slices $\left(10.83 \pm 0.25 \mathrm{~nm} /\right.$ wrap in DCC $^{+/+}$ internodes compared with $12.04 \pm 0.35$ $\mathrm{nm} /$ wrap in $\mathrm{DCC}^{-/-}$internodes; $p<$ 0.05).

\section{Netrin- 1 and DCC are enriched at CNS paranodes}

The lack of any obvious abnormalities in compact myelin is consistent with our previous subcellular fractionation of adult CNS white matter. These findings indicated that netrin-1 protein is not enriched in fractions containing compact myelin membranes, but that it is predominantly associated with fractions that include periaxonal and paranodal myelin membranes (Manitt et al., 2001). To further characterize the distribution of netrin- 1 and its receptors in CNS white matter, we performed immunohistochemical analyses to determine whether these proteins were enriched in these regions. In 30 DIV wildtype cerebellar slice cultures, netrin-1 and DCC immunoreactivity overlapped with the distribution of Caspr, which is concentrated at paranodes (Fig. $3 A-L$ ). The dis-

arrow). Paranodal loops oriented away from the axon were also frequently observed in the mutants ( $\boldsymbol{C}, \boldsymbol{G}$, arrows). Regions of myelin decompaction resembling paranodal loops were also present in mutant internodal myelin $(\boldsymbol{D}, \boldsymbol{H}, \boldsymbol{I})$. Magnification: $\boldsymbol{A}-\boldsymbol{H}, 68,000 \times ; \boldsymbol{I}, 25,000 \times$. Scale bars: $\boldsymbol{A}-\boldsymbol{H}, 200$ $\mathrm{nm} ; \boldsymbol{I}, 500 \mathrm{~nm} ; \boldsymbol{A}, \boldsymbol{B}, \boldsymbol{E}, \boldsymbol{F}$, insets, $100 \mathrm{~nm}$. 
tributions of netrin-1 and DCC protein were then examined immunohistochemically in adult rat spinal cord. Netrin-1 immunoreactivity colocalized with Caspr at the paranode in longitudinal sections, and DCC immunoreactivity was found in close proximity to the paranode (Fig. $3 M-X)$. In axonal cross sections, netrin- 1 immunoreactivity is closely associated with, and partially overlaps, that of Caspr (Fig. 3D-F, $P-R)$, consistent with an enrichment of netrin-1 in regions in which the oligodendroglial paranodal loops closely appose the axonal surface. DCC immunoreactivity surrounded the axon at the paranode, but unlike netrin-1, it extended beyond the area delimited by Caspr (Fig. 3J-L, $V-X)$. This is consistent with DCC localization to the oligodendroglial paranodal membrane loops, but not restricted to the region of axoglial contact.

Lack of DCC and netrin-1 leads to abnormalities in paranodal organization

The enrichment of netrin-1 and DCC protein at the paranodal region, as well as previous reports describing roles for netrins mediating short-range cell-cell and cell-matrix interactions (for review, see Baker et al., 2006), raises the possibility that netrin-1 may regulate axo-oligodendroglial interactions. To address this, paranodal regions in longterm cerebellar slice cultures derived from newborn netrin-1 ${ }^{-1-}$ and DCC $^{-1-}$ mice and their wild-type littermates were examined by transmission electron microscopy.

The paranodal axoglial junction is composed of sequences of cytoplasmcontaining loops of myelin membrane that tightly associate with each other and the axonal surface. In electron micrographs of myelinated axons, electrondense transverse bands mark points of contact between paranodal myelin loops and the axolemma (for review, see $\mathrm{Pe}$ draza et al., 2001). In electron micrographs of wild-type cerebellar slice cultures, paranodal loops were regularly spaced, and transverse bands were present in which each loop of glial mem-

brane contacted the axon (Fig. $4 A, E$ ), consistent with the appearance of these structures in vivo.

In long-term wild-type cerebellar slices, transverse bands and interloop densities were readily detected at the vast majority of paranodes (Fig. $4 A, E$ ). In contrast, paranodes in DCC $^{-1-}$ and netrin $-1^{-1-}$ slices were frequently disorganized (Fig. $4 B-D$, $F-H)$. Transverse bands were often absent and, when present, were frequently diffuse (Fig. $4 B, F$, insets). Glial loops were abnormally separated from each other, resulting in a loss of interloop densities (Fig. $4 B$ ). Glial membranes without axonal contact were frequently observed (Fig. $4 B, F$ ), and everted glial loops, oriented away from the axon, were common (Fig. $4 C, G)$. Occa-

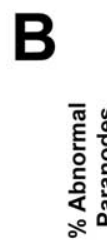

D
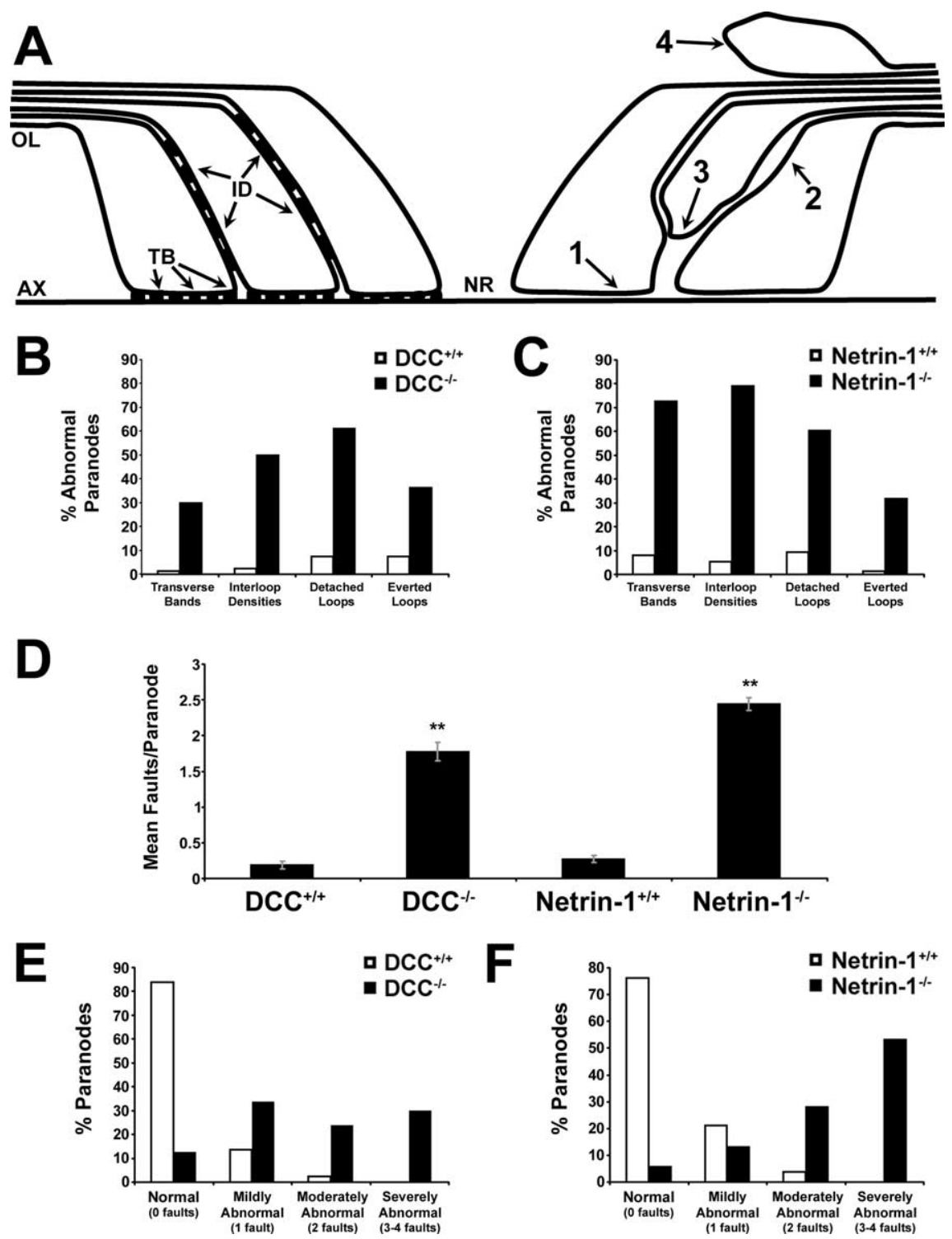

Figure 5. Quantification of paranodal defects in the absence of netrin-1 or DCC. The integrity of paranodal myelin was analyzed in electron micrographs of transverse sections of long-term cerebellar slice cultures derived from DCC ${ }^{-1-}$ (67 DIV) or netrin$1^{-1-}$ (49 DIV) mice and their wild-type littermates. $\boldsymbol{A}$, Myelin paranodes were examined for four defects: lack of transverse bands (1), lack of interloop densities (2), separation of paranodal myelin loops from the axonal surface (3), and everted paranodal loops (4). Each observation was counted as one fault. $B, C$, In both netrin and DCC mutants, the incidence of each of the four defects was classified as normal (0 faults), mildly abnormal (1 fault), moderately abnormal (2 faults), and severely abnormal (3-4 faults). abnormal, not a single wild-type paranode was severely abnormal. OL, Oligodendroglial membrane; AX, axolemma; TB, transverse bands; ID, interloop densities. ${ }^{* *} p<0.005$. Error bars indicate SEM.

sionally, noncompact paranode-like myelin membranes were localized to internodal regions (Fig. $4 D, H, I$ ).

To quantify the differences between wild-type and DCC- or netrin-1-deficient paranodes in long-term cultures, paranodes were scored for the presence of each of four faults (Fig. 5A): (1) absence of transverse bands, (2) absence of interloop densities and abnormal separation between glial loops, (3) detachment of paranodal loops from the axolemma, and (4) presence of everted loops. In both DCC (Fig. $5 B$ )- and netrin-1 (Fig. 5C)-deficient slices, all four faults were more frequent than in cultures obtained from wild-type littermates. On average, DCC $^{-1-}$ paranodes scored $1.78 \pm 0.13$ faults per para- 

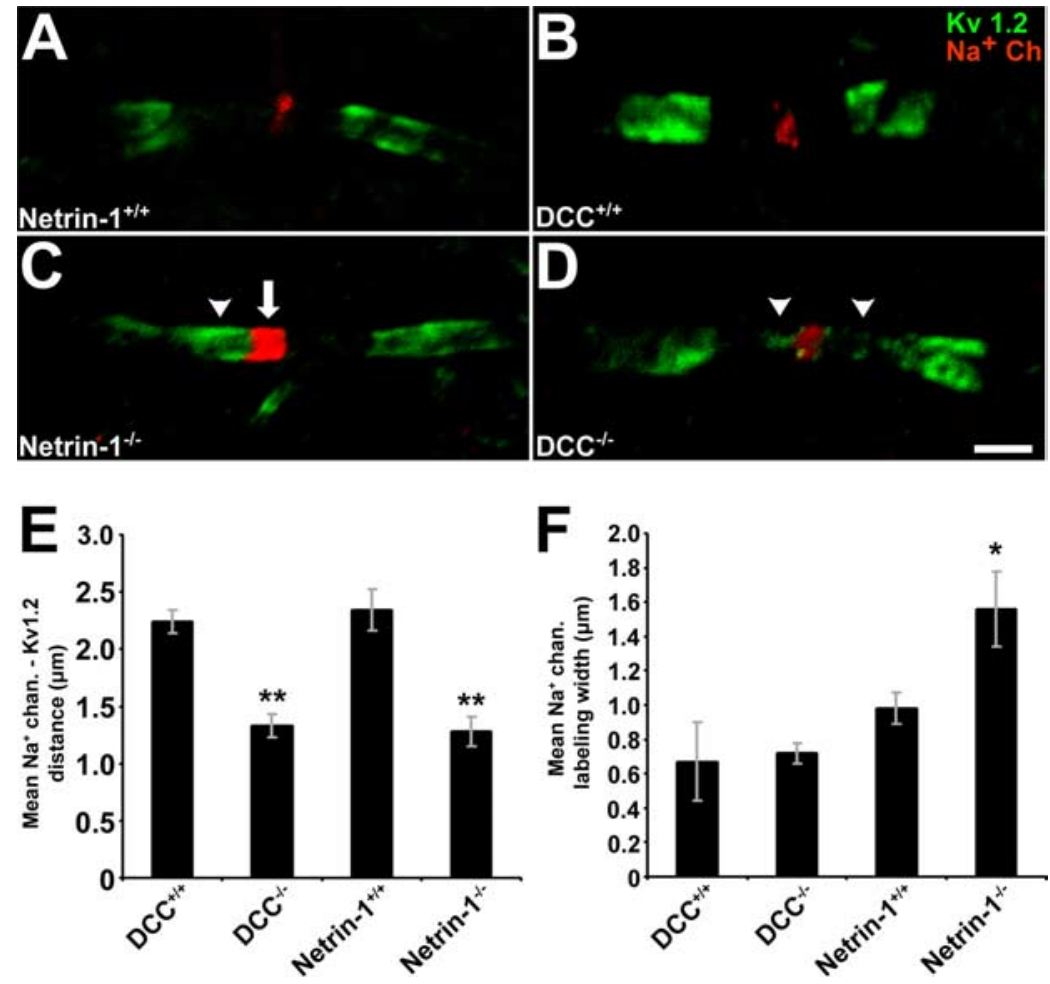

Figure 6. Disruption of the domain organization of the node of Ranvier in long-term netrin-1- and DCC-deficient slice cultures. Long-term (60 DIV) cerebellar slice cultures were double-labeled with antibodies against $\mathrm{Na}^{+}$ch and Kv1.2 (A-D). Kv1.2 protein was visualized using Alexa 488-conjugated secondary antibodies (green), and $\mathrm{Na}^{+}$ch proteins were visualized using Alexa 546-conjugated secondary antibodies (red). In cultures lacking netrin- $1(\boldsymbol{C})$ or DCC (D), a reduced distance between $\mathrm{Na}^{+}$channels localized within the node of Ranvier and $\mathrm{K}^{+}$channels normally localized to the juxtaparanodal region was detected. This decrease was primarily attributable to the apparent "leaking" of $\mathrm{K}^{+}$channels into the paranode, and occasionally the node itself $(\boldsymbol{C}, \boldsymbol{D}$, arrowheads; $E$ ). In netrin- $1^{-1-}$, but not $\mathrm{DCC}{ }^{-1-}$ slices, the length of the $\mathrm{Na}^{+}$ch-positive domain was increased relative to control $(\boldsymbol{C}$, arrow; $\boldsymbol{F})$. Magnification: $100 \times$ objective; digital zoom, 4. Scale bar, $2 \mu \mathrm{m} .{ }^{*} p<0.05,{ }^{* *} p<0.005$. Error bars indicate SEM.

node compared with $0.18 \pm 0.05$ for wild-type paranodes $(p<0.005)$, whereas netrin-1 ${ }^{-/-}$paranodes were more severely disorganized, scoring a mean of $2.43 \pm 0.09$ faults per paranode compared with $0.27 \pm 0.05$ for wild-type paranodes $(p<0.005)$ (Fig. 5D; supplemental Table 2, available at www. jneurosci.org as supplemental material). When paranodes were binned according to the number of faults, $>50 \%$ of netrin $^{-1-}$ paranodes and $\sim 30 \%$ of $\mathrm{DCC}^{-1-}$ paranodes, were classified as "severely abnormal," having three to four faults per paranode (Fig. 5E,F; supplemental Table 3, available at www.jneurosci.org as supplemental material). Consistent with these trends, quantification of the number of aberrant paranodal loops revealed a fourfold to sevenfold increase in everted loops and a 6- to 10-fold increase in detached loops in DCC $^{-1-}$ and netrin-1 $1^{-l-}$ compared with wild type (supplemental Table 4, available at www.jneurosci.org as supplemental material).

\section{The organization of paranodal and juxtaparanodal domains} requires netrin- 1 and $\mathrm{DCC}$

The paranodal axoglial apparatus has been described to act as a barrier, preventing the diffusion of potassium channels from the juxtaparanode into the paranode (for review, see Poliak and Peles, 2003). To investigate whether the ultrastructural abnormalities present in the netrin-1- or DCC-deficient slices result in a failure of the paranode to properly segregate nodal sodium channels $\left(\mathrm{Na}^{+} \mathrm{ch}\right)$ and juxtaparanodal potassium channels (Kv1.2), we measured the distance between the $\mathrm{Na}^{+} \mathrm{ch}$ and Kv1.2immunoreactive domains and the length of the $\mathrm{Na}^{+}$ch-immunoreactive band (Fig. 6; supplemental Table 5, available at www. jneurosci.org as supplemental material). In wild-type cultures, a clear gap was visible between nodal $\mathrm{Na}^{+} \mathrm{ch}$ and juxtaparanodal Kv1.2 immunoreactivity (Fig. 6A, $B$ ). In netrin- $1^{-1-}$ and DCC ${ }^{-1-}$ cultures, however, Kv1.2 immunoreactivity was often inappropriately localized to the paranode (Fig. 6C,D, arrowheads), and the mean distance between $\mathrm{Na}^{+} \mathrm{ch}$ and Kv1.2 immunoreactivity was reduced in netrin$1^{-1-}$ and $\mathrm{DCC}^{-1-}$ cultures relative to wild-type cultures (Fig. $6 E$ ). In addition, the $\mathrm{Na}^{+}$ch-immunoreactive domain was lengthened by $\sim 1.5$-fold in netrin$1^{-1-}$ nodes relative to netrin- $1^{+/+}$ nodes (Fig. $6 A, C$, arrow; $F$ ), but no such increase was observed in $\mathrm{DCC}^{-1-}$ nodes (Fig. 6B,D,F). These data indicate that the paranodal axoglial junction fails to appropriately constrain the localization of ion channels at nodes of Ranvier lacking netrin- $1^{-/-}$or $\mathrm{DCC}^{-/-}$. Furthermore, as suggested by the increased severity of the netrin-1 ${ }^{-/-}$ultrastructural phenotype, the failure of the paranodal barrier appears to be more severe in the absence of netrin-1, because $\mathrm{Na}^{+}$ch localization is also affected.

Localization of Caspr and neurofascin in $\mathrm{DCC}^{-/-}$and netrin-1 ${ }^{-/-}$paranodes Nfc155 and Caspr are concentrated at paranodal oligodendroglial and neuronal membranes, respectively, and are essential components of a protein complex required for paranodal organization (Tait et al., 2000; Bhat et al., 2001; Charles et al., 2002; Sherman et al., 2005). In previous studies of mutant animals with disruption of paranodal organization, the distribution of nfc155 and Caspr is aberrantly diffuse along myelinated axons instead of concentrated at paranodes (Marcus et al., 2002). Using antibodies that recognize either neurofascin, both 155 and $186 \mathrm{kDa}$ isoforms, or Caspr, we investigated whether loss of netrin-1 or DCC function affects the expression or localization of these proteins (Figs. 7, 8; supplemental Table 5, available at www.jneurosci.org as supplemental material). Neurofascin localization is not altered in DCC $^{-1-}$ (Fig. $7 A-D$ ) or netrin-1 $1^{-1-}$ slices (Fig. $8 A-D$ ), and the length of the neurofascin-immunoreactive domain is not affected in paranodal regions lacking DCC or netrin-1 (supplemental Table 5, available at www.jneurosci.org as supplemental material). In contrast, the region of Caspr immunoreactivity flanking $\mathrm{DCC}^{-1-}$ and netrin- $1^{-1-}$ nodes of Ranvier is markedly lengthened relative to that observed in cultures derived from their wild-type littermates (supplemental Table 5, available at www.jneurosci.org as supplemental material). Specifically, the Caspr-immunopositive domain expands from $2.84 \pm 0.14 \mu \mathrm{m}$ in DCC $^{+/+}$paranodes to $4.99 \pm 0.28 \mu \mathrm{m}$ in DCC $^{-/-}$paranodes $(p<$ $0.05)$, and from $3.76 \pm 0.16 \mu \mathrm{m}$ to $5.47 \pm 0.29 \mu \mathrm{m}$ in netrin $-1^{+/+}$ and netrin- $1^{-/-}$paranodes $(p<0.005)$, respectively. 


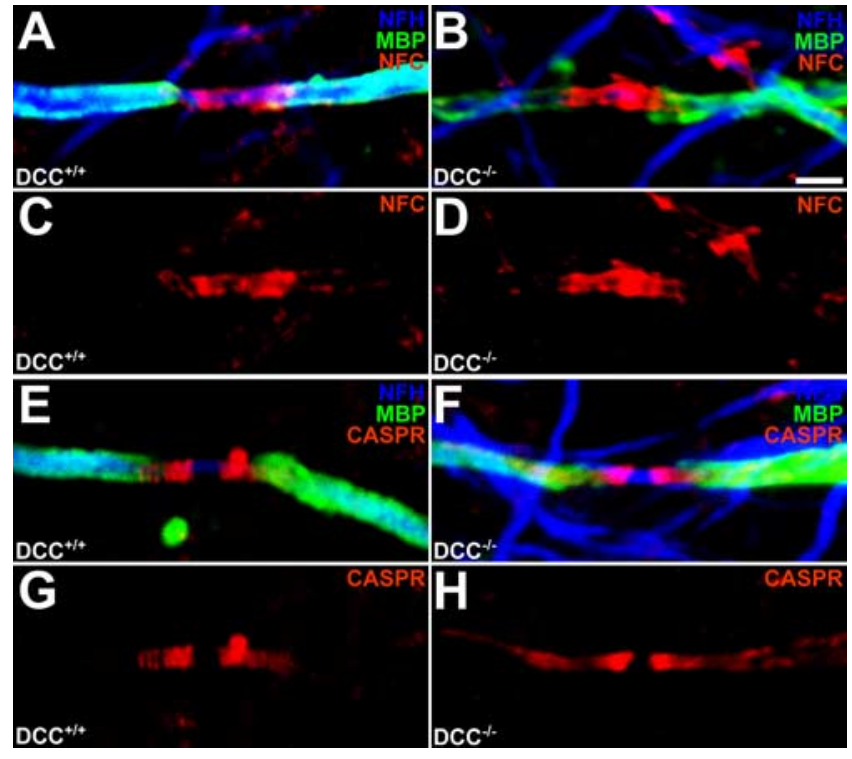

Figure 7. Caspr, but not neurofascin, distribution is altered in long-term DCC-deficient cultures. Long-term (60 DIV) cerebellar slice cultures were triple-labeled with antibodies against NFH, MBP, and either nfc $(\boldsymbol{A}-\boldsymbol{D})$ or Caspr $(\boldsymbol{E}-\boldsymbol{H})$. MBP was visualized using Alexa 488conjugated secondary antibodies (green), NFH was visualized using Alexa 633-conjugated secondary antibodies (blue), and nfc or Caspr were visualized using Alexa 546-conjugated secondary antibodies (red). The length of nfc-immunoreactive bands were unchanged between $D C C^{-1-}$ and $\mathrm{DCC}{ }^{+/+}$nodal regions, whereas Caspr-immunoreactive domains were lengthened at $D C C^{-1-}$ paranodes relative to wild-type slices (supplemental Table 5, available at www.jneurosci.org as supplemental material). Magnification: $100 \times$ objective; digital zoom, 4 . Scale bar, $2 \mu \mathrm{m}$.

\section{Netrin- 1 and DCC are required for the maintenance of CNS paranodal junctions}

Descriptions of aberrant paranodal organization in mutant mouse strains have reported junctions that form normally, but later become disorganized (Marcus et al., 2002; SchaerenWiemers et al., 2004; Rasband et al., 2005). To determine whether paranode formation occurs normally in netrin-1 and DCC mutants, we examined the organization of paranodal myelin in short-term (25 DIV) cerebellar slice cultures.

In wild-type cultures at 25 DIV, paranodal loops were regularly spaced and transverse bands were present, confirming that paranodal junctions had formed and matured fully by this stage (Fig. 9A,F). In contrast to what we observed in long-term cultures, 25 DIV netrin- $1^{-1-}$ and DCC $^{-l-}$ paranodes were indistinguishable from netrin ${ }^{+/+}$and $\mathrm{DCC}^{+/+}$paranodes (Fig. $9 B, G$ ), indicating that netrin- 1 and DCC are not required for the development of paranodal axoglial contacts. Quantification of the faults observed in long-term cultures, revealed no significant increase in any one fault in the absence of either netrin-1 or DCC at 25 DIV (Fig. 9C,H; supplemental Table 2, available at www. jneurosci.org as supplemental material), and the mean number of faults per paranode did not significantly differ between netrin$1^{-1-}$ or DCC ${ }^{-1-}$ and wild-type cultures (Fig. $9 D, I$; supplemental Table 2, available at www.jneurosci.org as supplemental material). When the paranodes were binned as described above, the vast majority of both wild-type and mutant paranodes were classified as normal (Fig. 9E,J; supplemental Table 3, available at www.jneurosci.org as supplemental material).

Consistent with the lack of an abnormal ultrastructural phenotype, sodium and potassium channels were appropriately segregated at wild-type and netrin-1 or DCC-null nodes of Ranvier in 25 DIV cultures (supplemental Fig. $S 1 A-D$, available at www.

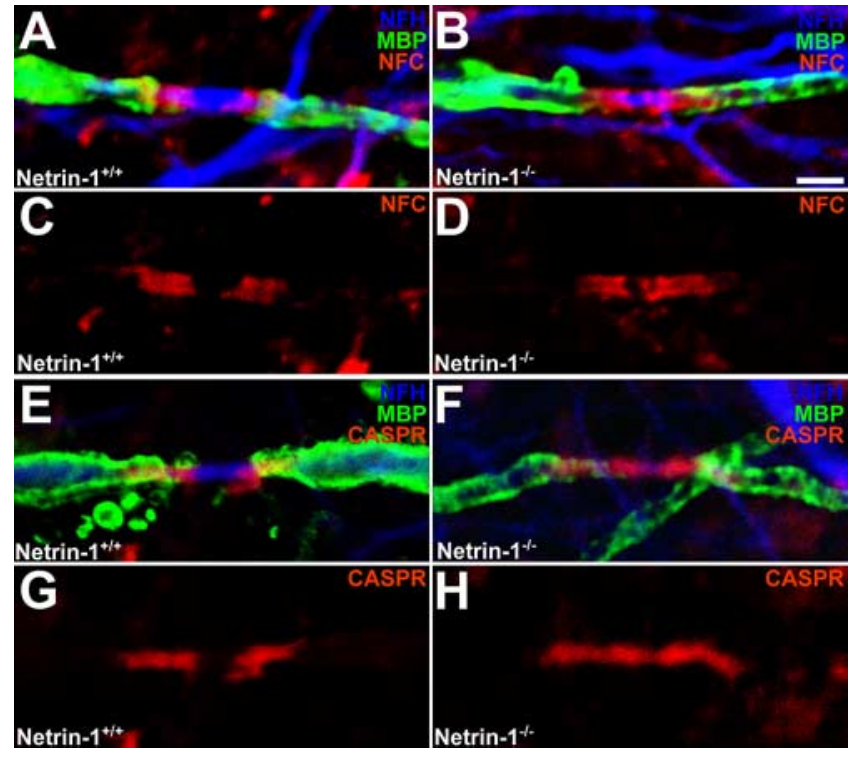

Figure 8. Caspr, but not neurofascin, distribution is altered in long-term netrin-1-deficient cultures. Long-term (60 DIV) cerebellar slice cultures were triple-labeled with antibodies against NFH, MBP, and either nfc $(\boldsymbol{A}-\boldsymbol{D})$ or Caspr $(\boldsymbol{E}-\boldsymbol{H})$. MBP was visualized using Alexa 488conjugated secondary antibodies (green), NFH was visualized using Alexa 633-conjugated secondary antibodies (blue), and nfc or Caspr were visualized using Alexa 546-conjugated secondary antibodies (red). The length of nfc-immunoreactive bands were unchanged between netrin- $1^{-/-}$and netrin- $1^{+/+}$nodal regions, whereas Caspr-immunoreactive domains were lengthened at netrin-1 ${ }^{-1-}$ paranodes relative to wild-type slices (supplemental Table 5, available at www.jneurosci.org as supplemental material). Magnification: $100 \times$ objective; digital zoom, 4. Scale bar, $2 \mu \mathrm{m}$

jneurosci.org as supplemental material). The distance separating $\mathrm{Na}^{+} \mathrm{ch}$ and Kv1.2-immunoreactive domains was unaltered in netrin-1 ${ }^{-1-}$ or DCC ${ }^{-1-}$ slices, and no increase in the length of the $\mathrm{Na}^{+}$ch-immunoreactive band was observed (supplemental Fig. $S 1 E-H$, supplemental Table 5, available at www.jneurosci. org as supplemental material).

Neurofascin was present in both 25 DIV wild-type and mutant cultures, and its distribution was unaltered in the absence of netrin-1 or DCC (supplemental Figs. S2, S3A-D, I; supplemental Table 5, available at www.jneurosci.org as supplemental material). The distribution of Caspr at netrin-1 ${ }^{-1-}$ or $\mathrm{DCC}^{-1-}$ paranodes in short-term cultures was indistinguishable from that observed in wild-type cultures (supplemental Figs. S2, S3E-H,J; supplemental Table 5, available at www.jneurosci.org as supplemental material), consistent with normal initial development of the paranodal region in the absence of netrin-1 or DCC.

The normal organization of paranodal axoglial junctions in short-term cultures and the disruption of the ultrastructure and domain organization in long-term cultures indicate that the defects observed in older netrin- $1^{-/-}$and DCC $^{-I-}$ cultures are not a consequence of aberrant myelin formation, but of maintenance of the axoglial junction.

\section{Disruption of paranodal domains formed by $\mathrm{DCC}^{-1-}$ oligodendrocytes in vivo}

To determine whether netrin signaling is similarly required for the maintenance of oligodendroglial paranodal junctions in vivo, we assessed the capacity of OPCs derived from $\mathrm{DCC}^{-1-}$ mice to myelinate retinal ganglion cell axons when transplanted into the eyes of wild-type mice. The axons of retinal ganglion cells are myelinated in the optic nerve; however, OPCs do not invade the retina during development and the proximal segment of the axon 

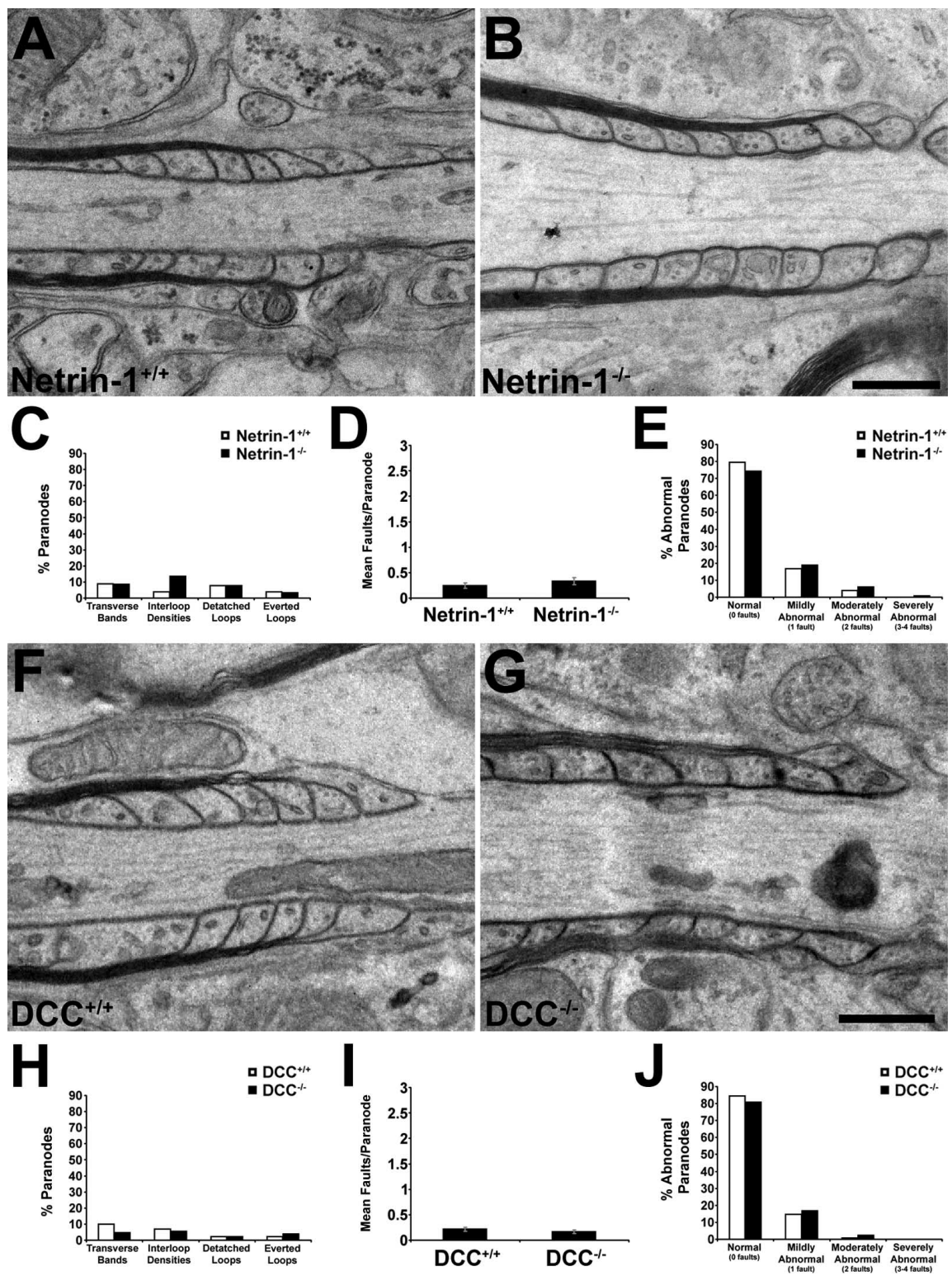

Figure 9. Normal ultrastructure of paranodal myelin in short-term netrin-1- and DCC-deficient cerebellar slice cultures. The organization of paranodal myelin was studied by transmission electron microscopy in short-term organotypic slice cultures derived from newborn netrin-1 ${ }^{-1-}$ or $D C C^{-1-}$ animals and their wild-type littermates $(\boldsymbol{A}, \boldsymbol{B} ; \boldsymbol{F}, \boldsymbol{G}$, respectively). At this age, paranodal myelin was well organized in both wild-type and mutant cultures. In almost every paranode studied at this age, transverse bands linked the axonal and oligodendrocyte membranes, and paranodal loops were closely apposed to each other. Detached and everted loops were rarely observed in short-term cultures $(\boldsymbol{C}-\boldsymbol{E}, \boldsymbol{H}-\boldsymbol{J})$. Magnification: $25,000 \times$. Scale bars, $500 \mathrm{~nm}$. Error bars indicate SEM.

within the retina remains unmyelinated (Berliner, 1931). Thus, the intraretinal segment of the ganglion cell axons provides a unique opportunity to assess the capacity of OPCs transplanted into the retina to myelinate, in the absence of competition from endogenous OPCs (Laeng et al., 1996). OPCs were isolated from mixed glial cultures derived from newborn $\mathrm{DCC}^{-1-}$ pups and their wild-type and heterozygote littermates. OPCs were then transplanted into the retina by intravitreal injection into the eyes of adult mice (Fig. 10A), and the retinas were isolated and analyzed 8 weeks later. None of the host retinas exhibited any signs of an immune response. Abundant MBP-immunopositive myelin segments were observed along retinal ganglion cell axons in eyes that received OPCs of all genotypes (Fig. 10 B). Paranodal specializations, visualized using the paranodal marker Caspr, were readily detected in newly myelinated axons (Fig. 10C-H). Quantitative analysis revealed a significant extension of the Caspr-immunoreactive domain, characteristic of a disrupted paranode structure, along retinal ganglion cell axons myelinated by $\mathrm{DCC}^{-1-}$ oligodendrocytes compared with control retinas myelinated by oligodendrocytes expressing DCC (Fig. $10 E-H)$. Specifically, the Casprimmunopositive domain expanded from $2.47 \pm 0.19 \mu \mathrm{m}(n=28)$ in paranodes expressing DCC to $3.14 \pm 0.15 \mu \mathrm{m}$ in DCC $^{-1-}$ paranodes $(n=40 ; p<0.01)$. Consistent with the phenotype found in cerebellar slice cultures lacking DCC or netrin-1, these findings indicate that netrin signaling through DCC regulates paranodal organization in the mature CNS in vivo. Importantly, these findings also indicate that the paranodal deficiencies detected result from the loss of a cellautonomous function of DCC in oligodendrocytes.

\section{Discussion}

Netrins function as long-range guidance cues that direct cell and axon migration, and also at short-range, regulating cellcell and cell-matrix adhesion (Baker et al., 2006). Signaling through its receptor DCC, netrin-1 directs the reorganization of F-actin by regulating FAK, fyn, PI3kinse, and the Rho-GTPases Cdc42 and Rac1 (Moore et al., 2007). In the adult CNS, expression of netrin-1 and its receptors is widespread in neuronal and glial cells including oligodendrocytes (Manitt et al., 2001, 2004). Using subcellular fractionation of CNS white matter, we previously demonstrated an enrichment of netrin-1 protein in noncompact myelin membranes implicated in axoglial contact (Manitt et al., 2001). Here, we show that netrin-1 and DCC are enriched in the paranodal region both in the adult CNS in vivo and in organotypic cerebellar cultures. Paranodal myelin developed normally in the absence of netrin-1 or DCC function, but became disorganized in mature myelin. Furthermore, our transplantation studies demonstrate a cell-autonomous requirement for DCC signaling in oligodendrocytes in vivo. We conclude that netrin-1 and DCC are required for the maintenance, but not the development, of CNS paranodal axoglial junctions.

The demonstration that paranodal loops form and mature normally but later became disordered in the absence of netrin-1 and DCC is consistent with a role for these proteins in the maintenance of axoglial junctions. Reports documenting CNS paranodal phenotypes in mice lacking CGT (Dupree et al., 1998, 1999; Marcus et al., 2002; Rasband et al., 2003), ceramide sulfotransferase $\left(\mathrm{CST}^{-1-}\right.$ ) (Ishibashi et al., 2002), MAL (Schaeren-Wiemers et al., 2004), 2',3'-cyclic nucleotide $3^{\prime}$ - 

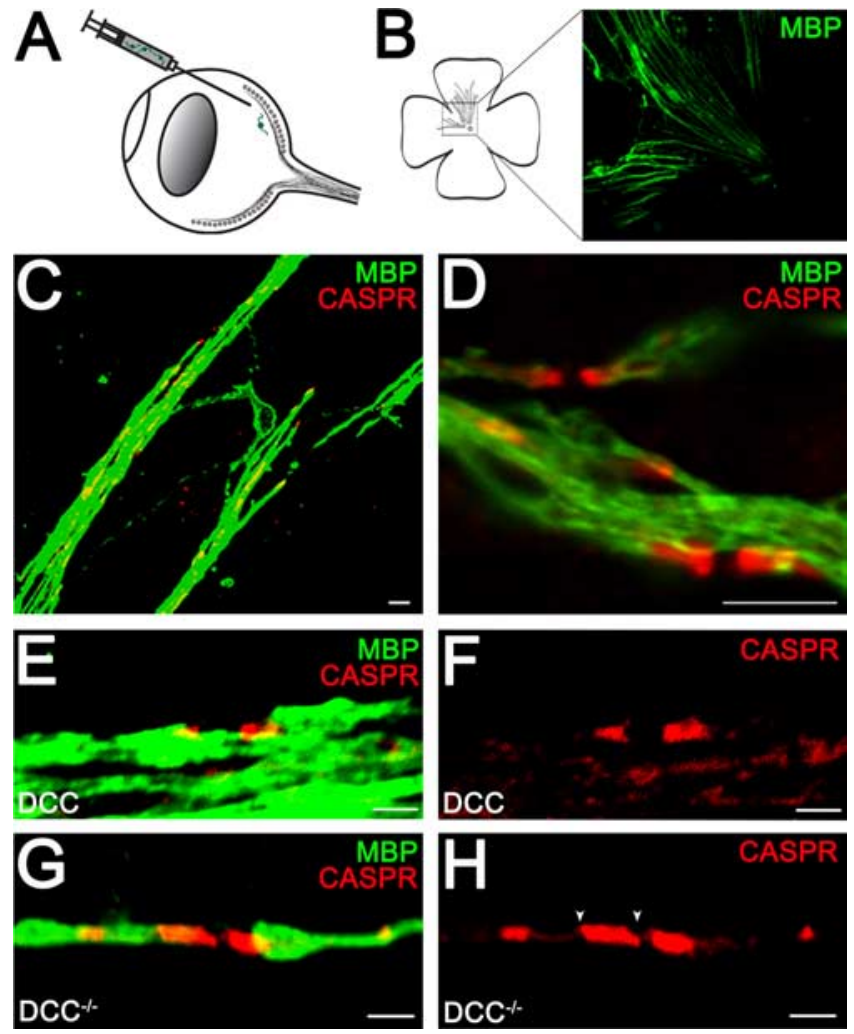

Figure 10. Altered paranodal Caspr distribution in retinal ganglion cell axons myelinated by $D C C^{-1-}$ oligodendrocytes in vivo. Injection of OPCs into the eyes of adult mice results in myelination $(\boldsymbol{A})$. Flat-mounted retina $(\boldsymbol{B})$ was double-labeled with antibodies against MBP to visualize myelin and Caspr to visualize paranodes $(\boldsymbol{C}-\boldsymbol{H})$. MBP was visualized using Alexa 488conjugated antibodies (green). Caspr was visualized using Alexa 546-conjugated antibodies (red). The Caspr-immunoreactive domains were lengthened in the DCC ${ }^{-/-}$myelin group (G, $\boldsymbol{H})$ compared with oligodendrocytes expressing $\operatorname{DCC}(\boldsymbol{E}, \boldsymbol{F})$. The white arrowheads $(\boldsymbol{H})$ illustrate the edges of the Caspr-immunoreactive domain measured. Magnification: $\boldsymbol{B}, 10 \times$ objective; $\boldsymbol{C}$, $100 \times$ objective; $\boldsymbol{D}, 100 \times$ objective; digital zoom, 2; $\boldsymbol{E}-\boldsymbol{H}, 100 \times$ objective; digital zoom, 4. Scale bars: $\boldsymbol{C}, \boldsymbol{D}, 5 \mu \mathrm{m} ; \boldsymbol{E}-\boldsymbol{H}, 2 \mu \mathrm{m}$.

phosphodiesterase ( $\mathrm{CNP}^{-/-}$) (Rasband et al., 2005), or CGTmyelin-associated glycoprotein (MAG) double mutants $\left(\mathrm{CGT}^{-1-}: \mathrm{MAG}^{-1-}\right.$ ) (Marcus et al., 2002), have described these gene products as being either directly or indirectly required for the maintenance of the paranodal region. In each case, the paranodes begin to develop normally and then become progressively disordered, but the age of onset and severity of disorganization of the paranodal region vary considerably among them. Significant differences exist, however, between previously reported maintenance phenotypes and those described here. Unlike in the absence of Caspr, contactin, neurofascin, CGT, or MAL, paranodes appear to mature completely in the absence of either netrin-1 or DCC. Caspr and neurofascin cluster, and well ordered transverse bands appear in a manner indistinguishable from cultures derived from wild-type cerebella. It is only after the paranodes have matured that the axoglial junction destabilizes. In all previous reports of paranodal maintenance phenotypes, transverse bands either do not form at all or develop abnormally. A second key distinction between the netrin-1 ${ }^{-1-}$ and DCC $^{-1-}$ phenotypes reported here and previous studies is that neurofascin remains localized to the paranodal region at longer time points, despite the ultrastructural defects and loss of domain segregation observed.

$\mathrm{Nfc155}$ present on the glial membrane is required for the re- cruitment of the axonal Caspr-contactin complex to the paranode (Sherman et al., 2005) and associates in trans with contactin in this complex (Bonnon et al., 2007). A plausible hypothesis is that, in the absence of netrin-1 or DCC, the disengagement of the oligodendroglial membrane from the axonal surface disrupts the interactions between $\mathrm{nfc} 155$ and the Caspr-contactin complex, freeing a proportion of these molecules to diffuse laterally along the axon and away from the paranode. This interpretation implies that, although the nfc155-Caspr-contactin complex is necessary, it is not sufficient for the maintenance of paranodal organization. Alternatively, the absence of netrin-1 or DCC may influence the localization of $\mathrm{nfc} 155$ to the paranodal plasma membrane, resulting in decreased availability of nfc155 to bind the Caspr-contactin complex. In this case, netrin-DCC signaling would be required to maintain the integrity of the nfc155-Casprcontactin complex at the paranode. A third possibility is that nfc155 and DCC may signal cooperatively through common downstream signaling effectors; however, because little is known regarding the intracellular signaling downstream of either DCC or nfc155 in oligodendrocytes, additional studies are necessary to elucidate the underlying mechanisms involved.

Although the phenotypes observed in netrin-1 ${ }^{-1-}$ and DCC $^{-1-}$ cerebellar slice cultures are similar, they are not identical. Minor increases in the periodicity of compact myelin (Fig. 2; supplemental Table 1, available at www.jneurosci.org as supplemental material) are observed in $\mathrm{DCC}^{-1-}$, but not netrin- $1^{-1-}$, slices. Meanwhile, the ultrastructural abnormalities observed in the netrin-1 mutant paranodes are more severe than those found in the DCC mutants, as evidenced by the significantly larger mean number of faults per paranode (Fig. 5D) and the greater number of paranodes scored to be severely abnormal (Fig. 5, compare $E, F)$. In addition, whereas potassium channel localization is aberrant in both $\mathrm{DCC}^{-/-}$and netrin-1 ${ }^{-/-}$paranodes, the sodium channel domain is also lengthened in the absence of netrin-1 (Fig. 6, compare $A, C$ with $B, D$ ). Spreading of the domain occupied by the sodium channels has been reported at CNS paranodes in $\mathrm{Caspr}^{-/-}$(Bhat et al., 2001) and CGT ${ }^{-/-}$(Dupree et al., 1999) mutant mice but not, for example, in MAL mutants (Schaeren-Wiemers et al., 2004). The increased severity of the netrin-1 $1^{-1-}$ phenotype suggests that netrin-1 function at the paranode may be mediated in part by a DCC-independent mechanism. Oligodendrocytes express UNC5 netrin receptors in the mature CNS (Manitt et al., 2004), and it remains to be determined how they may additionally contribute to netrin- 1 function at the paranode.

How, then, do netrin-1 and DCC contribute to the maintenance of paranodal axoglial junctions? Netrin-1 is a secreted protein; however, consistent with the restricted distribution of netrin- 1 found at paranodes, most netrin-1 in the CNS is not freely soluble but membrane-associated (Manitt et al., 2001). Furthermore, disrupting DCC function blocks cellular adherence to immobilized substrate-bound netrin-1, supporting roles for netrin-1 and DCC mediating cell-cell or cell-matrix adhesion (Shekarabi et al., 2005). These findings suggest that netrin-1 and DCC may directly contribute to adhesion between oligodendroglial paranodal loops and the axonal plasma membrane. Netrin-1 binds heparin with high affinity, and heparin sulfate proteoglycans have been hypothesized to localize netrin-1 on cell surfaces (Serafini et al., 1994; Kappler et al., 2000; Suzuki et al., 2006). Consistent with a potential role mediating adhesion at paranodes, recent findings have identified short-range roles for netrin-1 influencing tissue morphogenesis outside the CNS by 
regulating cell-cell interactions (for review, see Baker et al., 2006).

In neurons, DCC influences cytoskeletal organization and axon guidance by regulating the src family kinase fyn and the Rho-GTPases Cdc42 and Rac1 (Shekarabi and Kennedy, 2002; Li et al., 2004; Meriane et al., 2004; Shekarabi et al., 2005). Interestingly, loss of Cdc42 or Rac1 in oligodendroctyes results in disorganization of both compact and noncompact myelin membranes (Thurnherr et al., 2006). Fyn is also required for myelination in vivo (Sperber et al., 2001) and fyn-null oligodendrocytes do not form myelin-like membrane sheets in vitro (Osterhout et al., 1999). A similar defect in membrane sheet formation is detected when netrin-1 or DCC-null oligodendrocytes are allowed to mature in vitro, without neurons (S. Rajasekharan and T. E. Kennedy, unpublished data); however, the possibility that the regulation of Rho-GTPases and fyn by DCC and netrin-1 contributes to paranode maintenance remains to be investigated.

In summary, we conclude that netrin-1 and DCC are required to maintain the appropriate organization of axoglial membranes at CNS paranodal junctions. Our data identify an essential cellautonomous role for netrin-1 signaling through DCC during oligodendrocyte maturation and myelination, and support the hypothesis that DCC influences paranodal organization by regulating the local organization of the actin cytoskeleton and promoting axo-oligodendroglial adhesion. The novel phenotypes identified reveal a previously unknown mechanism required for axoglial adhesion and is the first identified function for netrin-1 and DCC in the mature CNS.

\section{References}

Baker KA, Moore SW, Jarjour AA, Kennedy TE (2006) When a diffusible axon guidance cue stops diffusing: roles for netrins in adhesion and morphogenesis. Curr Opin Neurobiol 16:529-534.

Berliner ML (1931) Cytologic studies on the retina. I. Normal coexistence of oligodendroglia and myelinated nerve fibers. Arch Ophthalmol 6:740-751.

Bhat MA, Rios JC, Lu Y, Garcia-Fresco GP, Ching W, St Martin M, Li J, Einheber S, Chesler M, Rosenbluth J, Salzer JL, Bellen HJ (2001) Axonglia interactions and the domain organization of myelinated axons requires neurexin IV/Caspr/Paranodin. Neuron 30:369-383.

Bonnon C, Bel C, Goutebroze L, Maigret B, Girault JA, Faivre-Sarrailh C (2007) PGY repeats and N-glycans govern the trafficking of paranodin and its selective association with contactin and neurofascin-155. Mol Biol Cell 18:229-241.

Boyle ME, Berglund EO, Murai KK, Weber L, Peles E, Ranscht B (2001) Contactin orchestrates assembly of the septate-like junctions at the paranode in myelinated peripheral nerve. Neuron 30:385-397.

Charles P, Tait S, Faivre-Sarrailh C, Barbin G, Gunn-Moore F, DenisenkoNehrbass N, Guennoc AM, Girault JA, Brophy PJ, Lubetzki C (2002) Neurofascin is a glial receptor for the paranodin/Caspr-contactin axonal complex at the axoglial junction. Curr Biol 12:217-220.

Chiu SY, Zhou L, Zhang CL, Messing A (1999) Analysis of potassium channel functions in mammalian axons by gene knockouts. J Neurocytol 28:349-364.

Dupree JL, Coetzee T, Blight A, Suzuki K, Popko B (1998) Myelin galactolipids are essential for proper node of Ranvier formation in the CNS. J Neurosci 18:1642-1649.

Dupree JL, Girault JA, Popko B (1999) Axo-glial interactions regulate the localization of axonal paranodal proteins. J Cell Biol 147:1145-1152.

Einheber S, Zanazzi G, Ching W, Scherer S, Milner TA, Peles E, Salzer JL (1997) The axonal membrane protein Caspr, a homologue of neurexin $\mathrm{IV}$, is a component of the septate-like paranodal junctions that assemble during myelination. J Cell Biol 139:1495-1506.

Faivre-Sarrailh C, Gauthier F, Denisenko-Nehrbass N, Le Bivic A, Rougon G, Girault JA (2000) The glycosylphosphatidyl inositol-anchored adhesion molecule F3/contactin is required for surface transport of paranodin/ contactin-associated protein (caspr). J Cell Biol 149:491-502.

Fazeli A, Dickinson SL, Hermiston ML, Tighe RV, Steen RG, Small CG,
Stoeckli ET, Keino-Masu K, Masu M, Rayburn H, Simons J, Bronson RT, Gordon JI, Tessier-Lavigne M, Weinberg RA (1997) Phenotype of mice lacking functional Deleted in colorectal cancer (Dcc) gene. Nature 386:796-804.

Foran DR, Peterson AC (1992) Myelin acquisition in the central nervous system of the mouse revealed by an MBP-Lac Z transgene. J Neurosci 12:4890-4897.

Ishibashi T, Dupree JL, Ikenaka K, Hirahara Y, Honke K, Peles E, Popko B, Suzuki K, Nishino H, Baba H (2002) A myelin galactolipid, sulfatide, is essential for maintenance of ion channels on myelinated axon but not essential for initial cluster formation. J Neurosci 22:6507-6514.

Jarjour AA, Manitt C, Moore SW, Thompson KM, Yuh SJ, Kennedy TE (2003) Netrin-1 is a chemorepellent for oligodendrocyte precursor cells in the embryonic spinal cord. J Neurosci 23:3735-3744.

Kappler J, Franken S, Junghans U, Hoffmann R, Linke T, Müller HW, Koch KW (2000) Glycosaminoglycan-binding properties and secondary structure of the C-terminus of netrin-1. Biochem Biophys Res Commun 271:287-291.

Laeng P, Molthagen M, Yu EG, Bartsch U (1996) Transplantation of oligodendrocyte progenitor cells into the rat retina: extensive myelination of retinal ganglion cell axons. Glia 18:200-210.

Li W, Lee J, Vikis HG, Lee SH, Liu G, Aurandt J, Shen TL, Fearon ER, Guan JL, Han M, Rao Y, Hong K, Guan KL (2004) Activation of FAK and Src are receptor-proximal events required for netrin signaling. Nat Neurosci 7:1213-1221.

Manitt C, Colicos MA, Thompson KM, Rousselle E, Peterson AC, Kennedy TE (2001) Widespread expression of netrin-1 by neurons and oligodendrocytes in the adult mammalian spinal cord. J Neurosci 21:3911-3922.

Manitt C, Thompson KM, Kennedy TE (2004) Developmental shift in expression of netrin receptors in the rat spinal cord: predominance of UNC-5 homologues in adulthood. J Neurosci Res 77:690-700.

Marcus J, Dupree JL, Popko B (2002) Myelin-associated glycoprotein and myelin galactolipids stabilize developing axo-glial interactions. J Cell Biol 156:567-577.

Menon K, Rasband MN, Taylor CM, Brophy P, Bansal R, Pfeiffer SE (2003) The myelin-axolemmal complex: biochemical dissection and the role of galactosphingolipids. J Neurochem 87:995-1009.

Meriane M, Tcherkezian J, Webber CA, Danek EI, Triki I, McFarlane S, Bloch-Gallego E, Lamarche-Vane N (2004) Phosphorylation of DCC by Fyn mediates Netrin-1 signaling in growth cone guidance. J Cell Biol 167:687-698.

Moore SW, Tessier-Lavigne M, Kennedy TE (2007) Netrins and their receptors. Adv Exp Med Biol 621:17-31.

Notterpek LM, Bullock PN, Malek-Hedayat S, Fisher R, Rome LH (1993) Myelination in cerebellar slice cultures: development of a system amenable to biochemical analysis. J Neurosci Res 36:621-634.

Osterhout DJ, Wolven A, Wolf RM, Resh MD, Chao MV (1999) Morphological differentiation of oligodendrocytes requires activation of Fyn tyrosine kinase. J Cell Biol 145:1209-1218.

Pedraza L, Huang JK, Colman DR (2001) Organizing principles of the axoglial apparatus. Neuron 30:335-344.

Poliak S, Peles E (2003) The local differentiation of myelinated axons at nodes of Ranvier. Nat Rev Neurosci 4:968-980.

Rasband MN, Taylor CM, Bansal R (2003) Paranodal transverse bands are required for maintenance but not initiation of Nav1.6 sodium channel clustering in CNS optic nerve axons. Glia 44:173-182.

Rasband MN, Tayler J, Kaga Y, Yang Y, Lappe-Siefke C, Nave KA, Bansal R (2005) CNP is required for maintenance of axon-glia interactions at nodes of Ranvier in the CNS. Glia 50:86-90.

Reynolds R, Wilkin GP (1988) Development of macroglial cells in rat cerebellum. II. An in situ immunohistochemical study of oligodendroglial lineage from precursor to mature myelinating cell. Development 102:409-425.

Rios JC, Melendez-Vasquez CV, Einheber S, Lustig M, Grumet M, Hemperly J, Peles E, Salzer JL (2000) Contactin-associated protein (Caspr) and contactin form a complex that is targeted to the paranodal junctions during myelination. J Neurosci 20:8354-8364.

Sapieha PS, Duplan L, Uetani N, Joly S, Tremblay ML, Kennedy TE, Di Polo A (2005) Receptor protein tyrosine phosphatase sigma inhibits axon regrowth in the adult injured CNS. Mol Cell Neurosci 28:625-635.

Schaeren-Wiemers N, Bonnet A, Erb M, Erne B, Bartsch U, Kern F, Mantei N, Sherman D, Suter U (2004) The raft-associated protein MAL is required 
for maintenance of proper axon-glia interactions in the central nervous system. J Cell Biol 166:731-742.

Schafer DP, Bansal R, Hedstrom KL, Pfeiffer SE, Rasband MN (2004) Does paranode formation and maintenance require partitioning of neurofascin 155 into lipid rafts? J Neurosci 24:3176-3185.

Serafini T, Kennedy TE, Galko MJ, Mirzayan C, Jessell TM, Tessier-Lavigne M (1994) The netrins define a family of axon outgrowth-promoting proteins homologous to C. elegans UNC-6. Cell 78:409-424.

Serafini T, Colamarino SA, Leonardo ED, Wang H, Beddington R, Skarnes WC, Tessier-Lavigne M (1996) Netrin-1 is required for commissural axon guidance in the developing vertebrate nervous system. Cell 87:1001-1014.

Shekarabi M, Kennedy TE (2002) The netrin-1 receptor DCC promotes filopodia formation and cell spreading by activating Cdc42 and Rac1. Mol Cell Neurosci 19:1-17.

Shekarabi M, Moore SW, Tritsch NX, Morris SJ, Bouchard JF, Kennedy TE (2005) Deleted in colorectal cancer binding netrin-1 mediates cell substrate adhesion and recruits Cdc42, Racl, Pak1, and N-WASP into an intracellular signaling complex that promotes growth cone expansion. J Neurosci 25:3132-3141.

Sherman DL, Tait S, Melrose S, Johnson R, Zonta B, Court FA, Macklin WB, Meek S, Smith AJ, Cottrell DF, Brophy PJ (2005) Neurofascins are required to establish axonal domains for saltatory conduction. Neuron 48:737-742.
Sperber BR, Boyle-Walsh EA, Engleka MJ, Gadue P, Peterson AC, Stein PL, Scherer SS, McMorris FA (2001) A unique role for Fyn in CNS myelination. J Neurosci 21:2039-2047.

Suzuki N, Toyoda H, Sano M, Nishiwaki K (2006) Chondroitin acts in the guidance of gonadal distal tip cells in C. elegans. Dev Biol 300:635-646.

Svenningsen AF, Shan WS, Colman DR, Pedraza L (2003) Rapid method for culturing embryonic neuron-glial cell cocultures. J Neurosci Res 72:565-573.

Tait S, Gunn-Moore F, Collinson JM, Huang J, Lubetzki C, Pedraza L, Sherman DL, Colman DR, Brophy PJ (2000) An oligodendrocyte cell adhesion molecule at the site of assembly of the paranodal axo-glial junction. J Cell Biol 150:657-666.

Tao-Cheng JH, Rosenbluth J (1983) Axolemmal differentiation in myelinated fibers of rat peripheral nerves. Brain Res 285:251-263.

Thurnherr T, Benninger Y, Wu X, Chrostek A, Krause SM, Nave KA, Franklin RJ, Brakebusch C, Suter U, Relvas JB (2006) Cdc42 and Rac1 signaling are both required for and act synergistically in the correct formation of myelin sheaths in the CNS. J Neurosci 26:10110-10119.

Vabnick I, Trimmer JS, Schwarz TL, Levinson SR, Risal D, Shrager P (1999) Dynamic potassium channel distributions during axonal development prevent aberrant firing patterns. J Neurosci 19:747-758.

Wang H, Kunkel DD, Martin TM, Schwartzkroin PA, Tempel BL (1993) Heteromultimeric $\mathrm{K}^{+}$channels in terminal and juxtaparanodal regions of neurons. Nature 365:75-79. 